\title{
Somatic Hypermutation
}

National Cancer Institute

\section{Source}

National Cancer Institute. Somatic Hypermutation. NCI Thesaurus. Code C162516.

The presence of a hypermutation phenotype in non-germline cells. 